\title{
Rancang Bangun Aplikasi Pengingat Kegiatan Akademik Berbasis Mobile
}

\author{
Findra Kartika Sari Dewi ${ }^{1}$, Theresia Devi Indriasari ${ }^{2}$, Yoris Prayogo ${ }^{3}$ \\ Program Studi Teknik Informatika, Universitas Atma Jaya Yogyakarta \\ J1. Babarsari 43, Yogyakarta 55281 \\ E-mail: ${ }^{1}$ findra@staff.uajy.ac.id, ${ }^{2}$ dev@staff.uajy.ac.id, ${ }^{3}$ yorisprayogo@gmail.com
}

Masuk: 2 Agustus 2016; Direvisi: 20 Agustus 2016; Diterima: 22 Agustus 2016

\begin{abstract}
Academic activities such as teaching and learning activities, exams for regular semester, practicse and final essay are daily operational activities that occur in an educational institution, especially in college. These have become routine. However, sometimes students and teachers forget the academic schedule, either because of changes in the schedule, or other reasons. Regular schedule changes are usually announced manually by the administration staff to students or lecturers with the use of a notice board. Therefore, an application is needed to help announcing the academic information in real time and to remind the lecturers and students to fulfill academic activities as scheduled. The target to be achieved is to provide an application as an academic reminder. The application consists of two parts, which are a web application to incorporate changes to the schedule, and a mobile application to display the daily schedule of academic activities along with the schedule reminder notification.
\end{abstract}

Keywords: schedule reminder, academic activities, mobile applications

Abstrak. Kegiatan akademik seperti kegiatan belajar mengajar, pelaksanaan ujian semester, ujian kerja praktek dan ujian tugas akhir (pendadaran) merupakan kegiatan operasional sehari-hari yang terjadi di sebuah lembaga pendidikan, khususnya di perguruan tinggi. Kegiatan belajar mengajar merupakan hal yang sudah menjadi rutinitas, namun masih seringkali terjadi, mahasiswa maupun dosen lupa dengan jadwal kegiatan akademik yang menjadi kewajibannya, entah karena adanya perubahan jadwal, ataupun alasan lainnya. Perubahan jadwal reguler biasanya didistribusikan oleh pihak Tata Usaha ke mahasiswa atau dosen secara manual melalui papan pengumuman. Oleh karena itu, dibutuhkan suatu aplikasi untuk membantu pendistribusian perubahan informasi akademik secara realtime dan mengingatkan dosen maupun mahasiswa untuk melaksanakan kegiatan akademik sesuai jadwal. Target yang ingin dicapai adalah menyediakan sebuah aplikasi pengingat jadwal kegiatan akademik. Aplikasi ini terdiri atas dua bagian, yaitu aplikasi web untuk memasukkan perubahan jadwal, dan aplikasi mobile yang digunakan untuk menampilkan jadwal kegiatan akademik harian berserta notifikasi pengingat jadwal tersebut.

Kata kunci: pengingat jadwal, kegiatan akademik, aplikasi mobile

\section{Pendahuluan}

Kegiatan akademik seperti kegiatan belajar mengajar (KBM), pelaksanaan ujian semester, ujian kerja praktek dan ujian tugas akhir/pendadaran merupakan kegiatan operasional sehari-hari yang terjadi di sebuah lembaga pendidikan, khususnya di perguruan tinggi. Salah satu upaya yang sudah dilakukan oleh beberapa perguruan tinggi di Indonesia untuk mencapai pelayanan akademik dan tata kelola yang berkualitas adalah melalui pemanfaatan Teknologi Informasi dan 
Komunikasi (TIK) berupa penggunaan sistem informasi akademik yang berperan untuk meningkatkan reputasi perguruan tinggi, serta meningkatkan kepuasan pengguna (Sultono, dkk., 2016). Penelitian yang sudah dilakukan pada seluruh perguruan tinggi di Bandung menunjukkan bahwa pemanfaatan sistem informasi akademik memiliki efektivitas implementasi yang cukup baik, serta menghasilkan keluaran yang baik (2013). Upaya untuk menjaga keberlangsungan kegiatan akademik di Universitas Atma Jaya Yogyakarta (UAJY) telah dilakukan beberapa tahun terakhir melalui berbagai cara, seperti adanya aturan pelaksanaan KBM untuk setiap mata kuliah minimal 12 kali dalam satu semester. Selain itu juga dengan adanya perangkat presensi menggunakan sidik jari, yang digunakan untuk mengontrol jadwal KBM agar waktu dan durasinya sesuai degan aturan yang berlaku. Meskipun KBM ini merupakan hal yang sudah menjadi rutinitas, namun masih seringkali terjadi, mahasiswa maupun dosen lupa dengan jadwal kegiatan akademik yang menjadi kewajibannya, entah karena adanya perubahan jadwal dari jadwal reguler, ataupun alasan lainnya.

Berdasarkan hasil wawancara pada 30 dosen dan mahasiswa di UAJY, mereka masih menggunakan cara-cara konvensional untuk mencatat kegiatan akademik yang harus mereka lakukan sehari-hari, seperti menuliskan di kertas dan ditempelkan di meja, menggunakan alarm, dan menggunakan aplikasi kalender di ponsel. Walaupun caranya berbeda-beda, namun intinya adalah bahwa masih dibutuhkan usaha proaktif dari dosen dan mahasiswa untuk mengingatkan dirinya akan kegiatan akademik tersebut. Dari usaha-usaha yang sudah mereka lakukan itu, ternyata juga masih ada jadwal yang luput dari ingatan mereka. Hal ini dikarenakan seperti adanya perubahan jadwal dari jadwal reguler, alarm yang lupa di-set, atau kesalahan persepsi saat membaca catatan jadwal yang dibuat.

Terkait dengan perubahan jadwal dari jadwal reguler, di UAJY proses pemindahan jadwal KBM ini juga masih dilakukan secara manual. Contohnya di Fakultas Teknologi Industri dimana dosen akan menuliskan pesan di sebuah buku yang disediakan di kantor Tata Usaha. Kemudian selanjutnya pesan ini akan dituliskan/diumumkan secara manual di papan tulis di lobby fakultas oleh pihak Tata Usaha. Hal ini juga menjadi sebuah permasalahan tersendiri bagi mahasiswa yang domisilinya jauh dari kampus. Seringkali mahasiswa mengalami kekecewaan ketika mengetahui bahwa jadwal KBM dimundurkan atau bahkan dipindahkan ke hari lain, padahal mahasiswa sudah terlanjur datang ke kampus.

Dari permasalahan diatas maka dibutuhkan suatu aplikasi untuk membantu pendistribusian perubahan informasi akademik secara realtime dan mengingatkan dosen maupun mahasiswa untuk melaksanakan kegiatan akademik sesuai jadwal. Penelitian yang dilakukan oleh penulis bertujuan untuk membangun aplikasi yang dapat digunakan sebagai pengingat jadwal kegiatan akademik di UAJY. Penelitian ini terbagi dalam dua tahap besar, pertama analisis dan perancangan aplikasi, kedua pembangunan aplikasi. Penelitian ini akan mengembangkan sistem dalam dua platform. Pertama, platform mobile yang digunakan dosen dan mahasiswa untuk melihat beberapa informasi agenda akademik dan menerima informasi/pengumuman realtime dan notifikasi/alarm terkait dengan kegiatan akademik. Kedua, platform web yang digunakan pihak Tata Usaha untuk melakukan broadcast pengumuman atau undangan kepada pengguna aplikasi mobile.

\section{Tinjauan Pustaka}

Selama lima tahun terakhir, piranti mobile seperti smartphone dan tablet (Kalinić \& Arsovski, 2009) lebih popular dibandingkan komputer desktop atau laptop. Semenjak IOS meluncurkan smartphone iPhone pada tahun 2007 dan Android merilis berbagai macam smartphone dan tablet di tahun 2008, sistem operasi mobile dan aplikasi mobile semakin popular dibandingkan sistem operasi dan aplikasi desktop (Lim, 2015). Aplikasi mobile adalah program aplikasi yang berjalan pada smartphone dan tablet. Aplikasi ini dikembangkan dan dijalankan 
pada sistem operasi mobile tertentu dan didistribusikan di marketplace seperti Google Play atau Apple App Store. Popularitas aplikasi mobile semakin meningkat sejalan dengan penyebarannnya di kalangan pengguna telepon seluler (Ludwig, 2012).

Aplikasi mobile yang hanya dapat berjalan pada satu platform saja, dengan menggunakan Software Development Kit (SDK) tertentu, tool, dan bahasa pemrograman tertentu yang disediakan oleh suatu vendor yang disebut dengan Native Application (Lim, 2015). Misalnya aplikasi mobile yang dikembangkan untuk framework Android tidak akan dapat berjalan di framework iOS. Kelemahan dari aplikasi native adalah bahwa proses pengembangannya membutuhkan waktu yang cukup lama untuk membuat aplikasi yang sama untuk beberapa platform yang berbeda. Kelebihannya adalah performanya baik dan dapat memaksimalkan utilitas sistem mobile dengan dukungan dari SDK dan Application Programmable Interface (API).

Aplikasi mobile yang dapat berjalan di beberapa platform dengan hanya satu kali proses pengembangan disebut dengan Hybrid Application (Lim, 2015). Aplikasi hybrid ini dapat berjalan pada semua piranti mobile yang mendukung teknologi web seperti HTML5, CSS dan JavaScript. Keuntungannya adalah desain dan implementasi antarmuka lebih mudah dengan didukung oleh teknologi HTML dan CSS. Kelemahannya adalah keterbatasan akses ke kemampuan low-level piranti mobile.

Push notification, yang juga sering disebut dengan server push notification, adalah penyampaian informasi dari sebuah aplikasi software ke sebuah perangkat komputasi tanpa permintaan khusus dari klien. Push notification ini berbeda dengan pull notification, yang mana klien harus terlebih dahulu meminta informasi dari sebuah server. Keuntungan dari push notification dalam komputasi mobile adalah bahwa teknologi ini tidak memerlukan aplikasi khusus pada perangkat mobile agar pesan dapat diterima. Hal ini memungkinkan smartphone untuk menerima dan menampilkan notifikasi bahkan ketika layar perangkat sedang terkunci dan aplikasi yang memberikan notifikasi sedang tidak berjalan. Perangkat dan layanan yang berbeda mengandalkan metode yang berbeda untuk menyampaikan push notification. Apple developer dapat menggunakan Apple Push Notification Service's Developers API agar aplikasi mereka dapat memberikan push notification ke perangkat iOS. Sedangkan untuk perangkat Android, dapat digunakan layanan Google Cloud Messaging (GCM) (Lee, 2011). GCM adalah layanan gratis yang memungkinkan pengembang untuk mengirim pesan antara server dan aplikasi klien. Ketika ada update baru, server akan langsung mengirimkan sebuah pesan (pemberitahuan) ke perangkat, dan kemudian aplikasi akan meminta update tersebut dari server (Kumar \& Kumar, 2013).

Berikut beberapa penelitian terdahulu terkait dengan aplikasi pengingat kegiatan akademik. Sujito dan Sundari (2011) melakukan penelitian yang menghasilkan aplikasi yang dapat memberikan pengingat secara otomatis untuk dosen pengajar yang mempunyai jadwal kuliah pada hari tersebut atau jadwal kuliah aktif, dan mampu memberikan informasi jadwal kuliah dan status kedatangan dosen pengajarnya secara real time. Aplikasi yang dibangun ini masih berbasis desktop dan mengirimkan notifikasi pengingat melalui pesan singkat (SMS). Akhmad (2013) melakukan penelitian yang menghasilkan aplikasi pengingat jadwal ujian semester untuk mahasiswa. Aplikasi ini dibangun untuk platform Android, namun masih membutuhkan keaktifan mahasiswa untuk melakukan input jadwal secara manual pada smartphone. Aplikasi ini belum terintegrasi dengan basis data kampus, sehingga tidak memberikan notifikasi pengingat dengan sumber data yang berasal dari kampus. Ramadhan dan Utomo (2014) melakukan penelitian yang menghasilkan aplikasi yang digunakan untuk memberikan notifikasi jadwal kuliah dan menampilkan kalender kegiatan bagi mahasiswa. Aplikasi ini hanya memberikan notifikasi ketika ada jadwal baru yang dikeluarkan oleh kampus. Aplikasi ini dibangun untuk platform Android. Randicha, dkk. (2014) melakukan penelitian yang menghasilkan aplikasi penjadwalan sidang tugas akhir. Aplikasi tersebut menyediakan informasi 
khususnya hasil penjadwalan sidang tugas akhir, serta menyediakan fasilitas pesan pengingat melalui SMS saat jadwal telah ditentukan dan saat ada perubahan jadwal. Aplikasi ini dibangun untuk platform web dan Android, ditambah dengan SMS. Studi yang dilakukan oleh penulis bermaksud untuk merancang dan membangun suatu aplikasi yang dapat membantu pendistribusian perubahan informasi akademik secara realtime dan memberikan notifikasi kepada dosen maupun mahasiswa untuk melaksanakan kegiatan akademik sesuai jadwal. Aplikasi yang dibangun terdiri atas dua bagian yaitu aplikasi web dan aplikasi mobile.

\section{Metodologi Penelitian}

Metodologi yang digunakan dalam penelitian ini terbagi dalam dua tahap besar. Tahap pertama terdiri dari beberapa subtahap, yakni: (1) Studi literatur, yang dilakukan untuk mendapatkan informasi terkait dengan aplikasi yang akan dibangun; (2) Wawancara langsung kepada dosen dan mahasiswa UAJY untuk memperoleh data serta informasi mengenai proses mengingat jadwal akademik di UAJY, serta untuk menentukan fitur-fitur yang dibutuhkan dalam aplikasi; (3) Analisis kebutuhan sistem, yang dilakukan untuk mengetahui kebutuhan sistem baik fungsional maupun nonfungsional dan akan menghasilkan spesifikasi sistem dan kebutuhan fungsionalitas yang harus tersedia dalam aplikasi; dan (4) Perancangan dan pembuatan mockup, yang dilakukan untuk menghasilkan rancangan aplikasi berdasarkan hasil analisis pada tahap sebelumnya. Hasil rancangan berupa arsitektur sistem, basis data, dan antarmuka sistem yang bersifat low fidelity prototype atau mockup. Sementara itu tahap kedua juga terdiri dari beberapa kegiatan: (5) Pembangunan aplikasi, yang dilakukan untuk menghasilkan aplikasi secara keseluruhan; dan (6) Pengujian aplikasi, yang dilakukan untuk mengetahui kelebihan dan kekurangan aplikasi baik dari aspek fungsionalitas maupun user acceptance.

\section{Hasil dan Pembahasan}

\subsection{Hasil Wawancara}

Wawancara langsung kepada dosen dan mahasiswa UAJY digunakan untuk memperoleh data serta informasi mengenai proses mengingat jadwal akademik di UAJY, dimana sudah dituliskan pada Bab 1. Berdasarkan hasil wawancara tersebut, ditentukan fitur-fitur yang dibutuhkan dalam aplikasi, yang secara rinci akan dituangkan bada subbab 4.2. dan subbab 4.3.

\subsection{Perancangan Aplikasi}

Gambar 1 sampai dengan Gambar 3 memperlihatkan sebagian hasil analisis dan perancangan dalam bentuk use case diagram. Aplikasi yang telah dirancang dan dibangun dibagi ke dalam dua platform, yaitu mobile dan web. Fungsionalitas masing-masing platform dapat dilihat pada use case diagram. Pada use case diagram untuk aplikasi mobile (Gambar 1) terdapat enam buah usecase yang merupakan fungsionalitas utama perangkat lunak ini yaitu: (1) login, (2) mengirim broadcast, (3) melihat kalender, (4) melihat broadcast, (5) melihat jadwal kuliah, dan (6) tambah event kalender. Pada use case diagram untuk aplikasi web (Gambar 2) terdapat tujuh buah usecase yaitu: (1) login, (2) mengirim broadcast, (3) membuat undangan pendadaran, (4) cetak undangan pendadaran, (5) mengirim undangan, (6) mengirim jadwal mengawas ujian, dan (7) pengelolaan kategori. Physical data model (Gambar 3) terdiri atas 11 buah tabel sesuai dengan kebutuhan aplikasi atas data-data yang akan disimpan di basis data. 


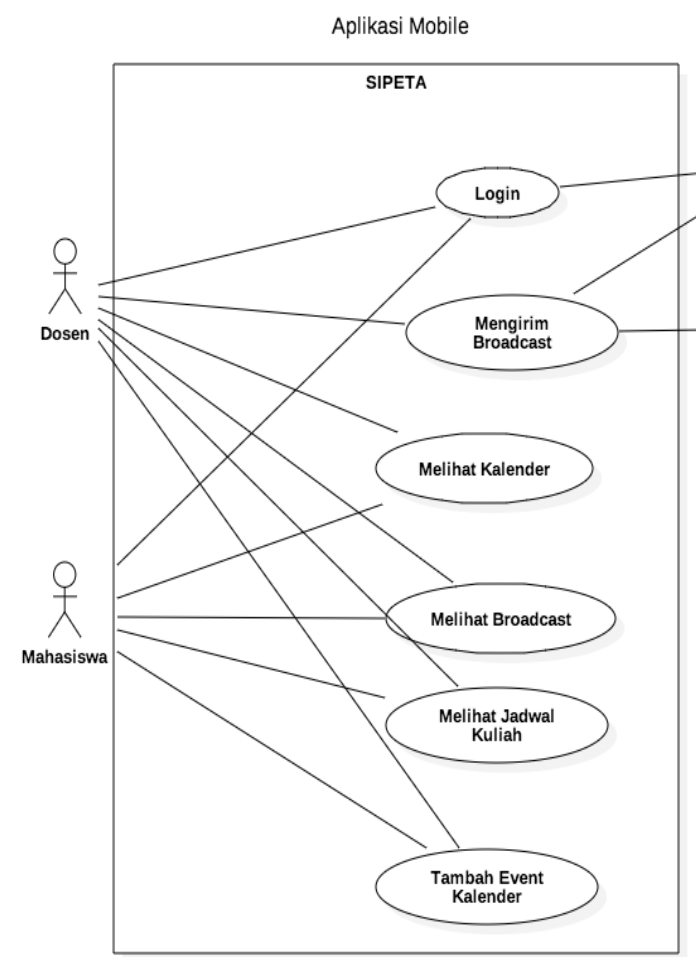

Gambar 1. Use case Aplikasi Mobile

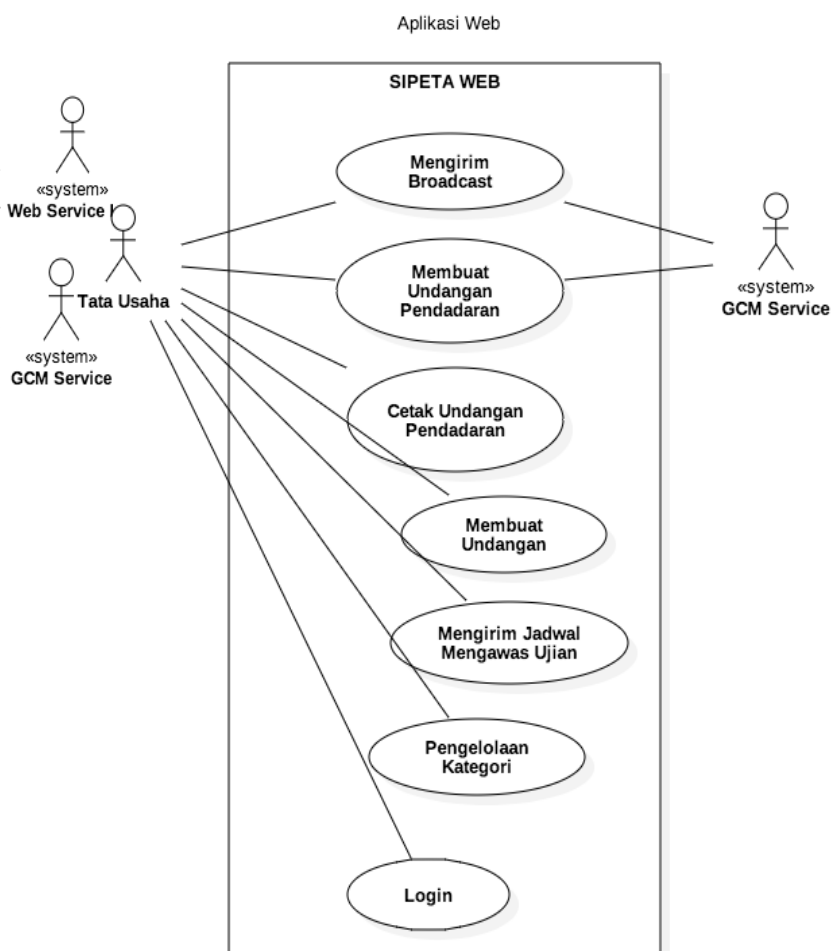

Gambar 2. Use case Aplikasi Web

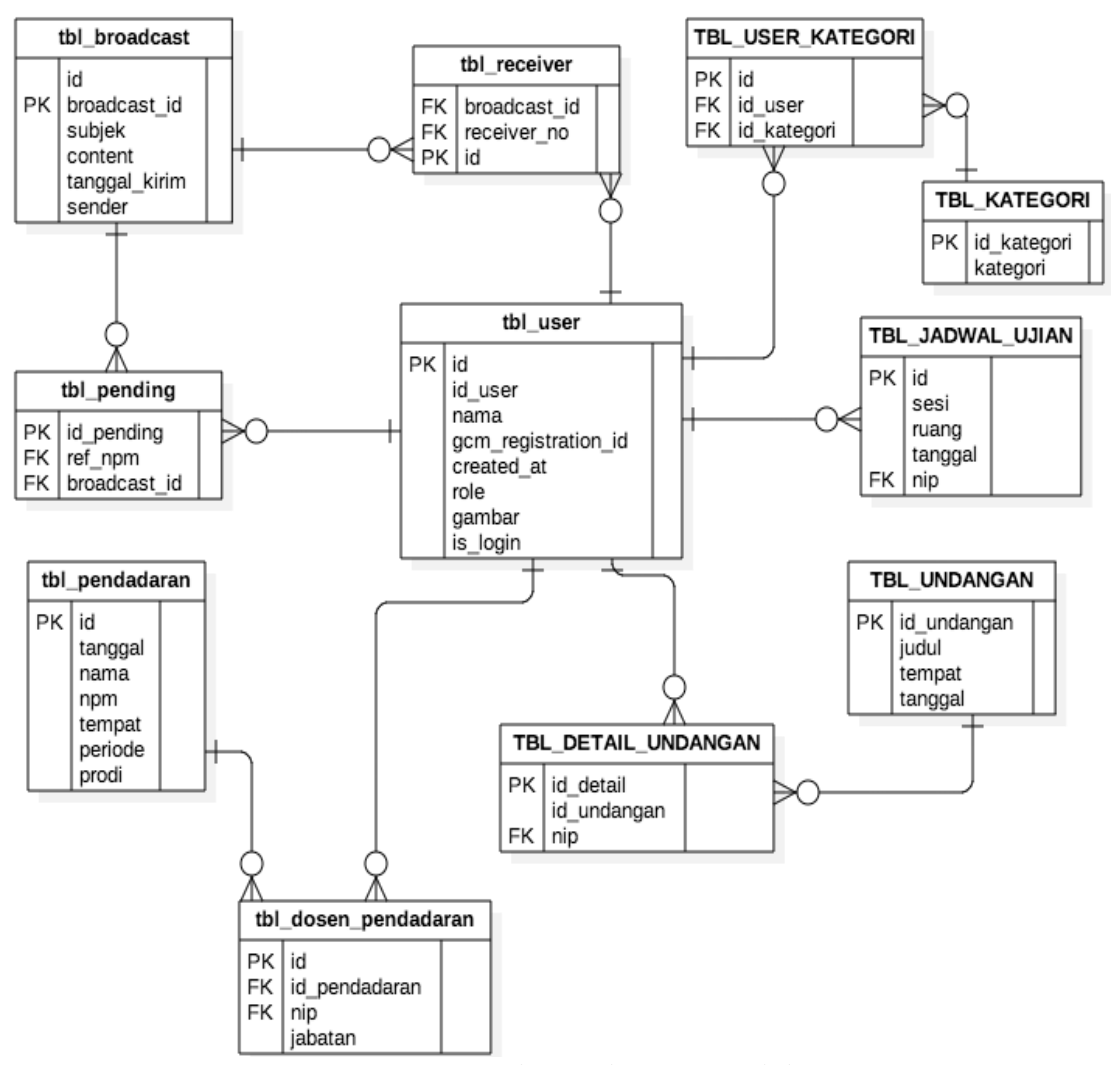

Gambar 3. Physical Data Model 


\subsection{Pembangunan Aplikasi}

Aplikasi yang telah dirancang dan dibangun merupakan aplikasi yang bertujuan sebagai pengingat kegiatan akademik. Aplikasi ini terbagi ke dalam dua bagian, aplikasi mobile dan aplikasi web. Aplikasi mobile yang dibangun baru sebatas berjalan pada sistem operasi Android minimal versi 4.1, sedangkan aplikasi web dapat berjalan pada browser apapun. Aplikasi ini memanfaatkan service GCM untuk mendukung fungsionalitas push notification. Gambar 4 sampai dengan Gambar 10 memperlihatkan beberapa tampilan antarmuka aplikasi mobile dan web yang telah dibangun. Aplikasi web digunakan oleh pengguna dosen dan mahasiswa, sedangkan aplikasi web digunakan oleh pihak Tata Usaha.

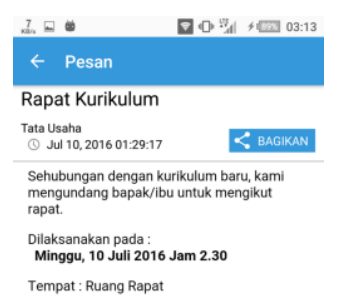

$\triangleleft \quad \triangle \quad \square$

Gambar 4. Tampil Pesan

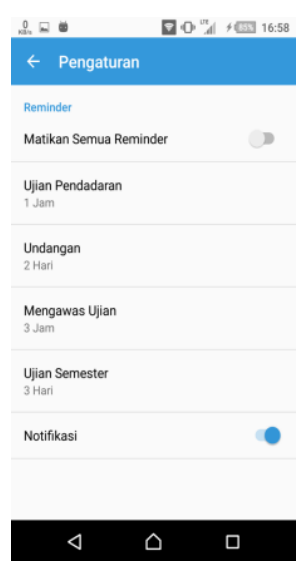

Gambar 5. Pengaturan Dosen

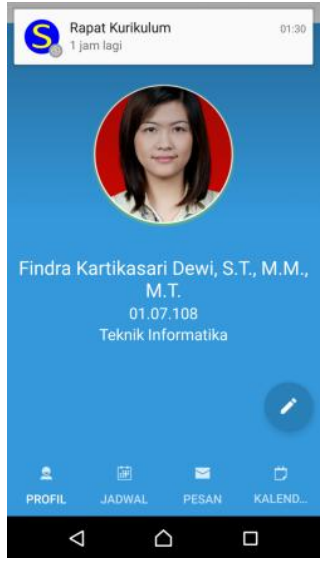

Gambar 6. Notifikasi untuk reminder/event

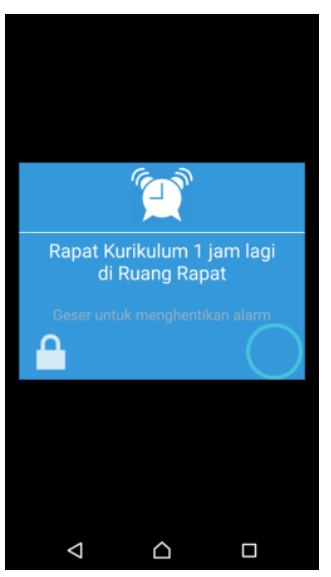

Gambar 7. Full alarm untuk reminder/event

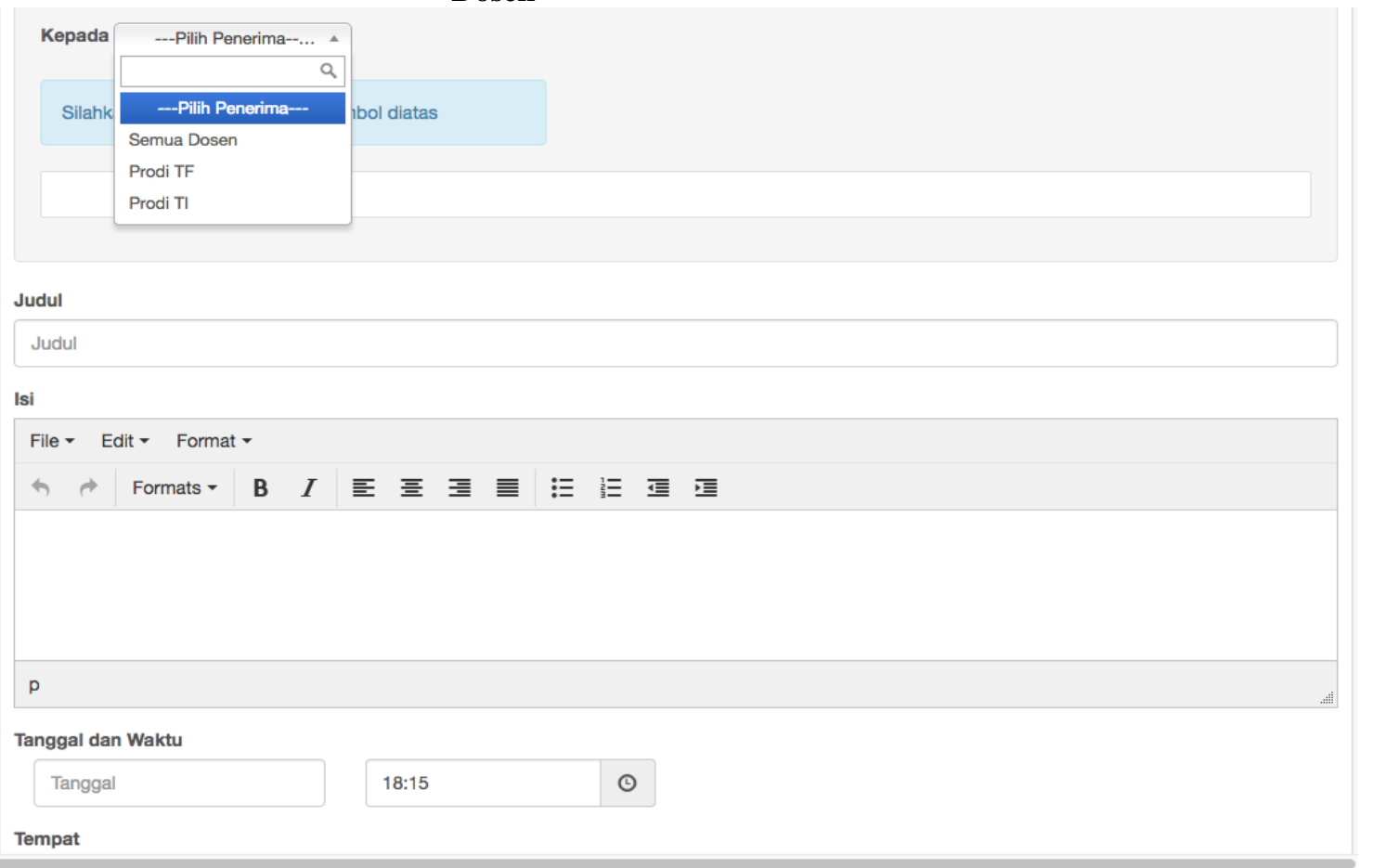

Gambar 8. Broadcast Undangan 


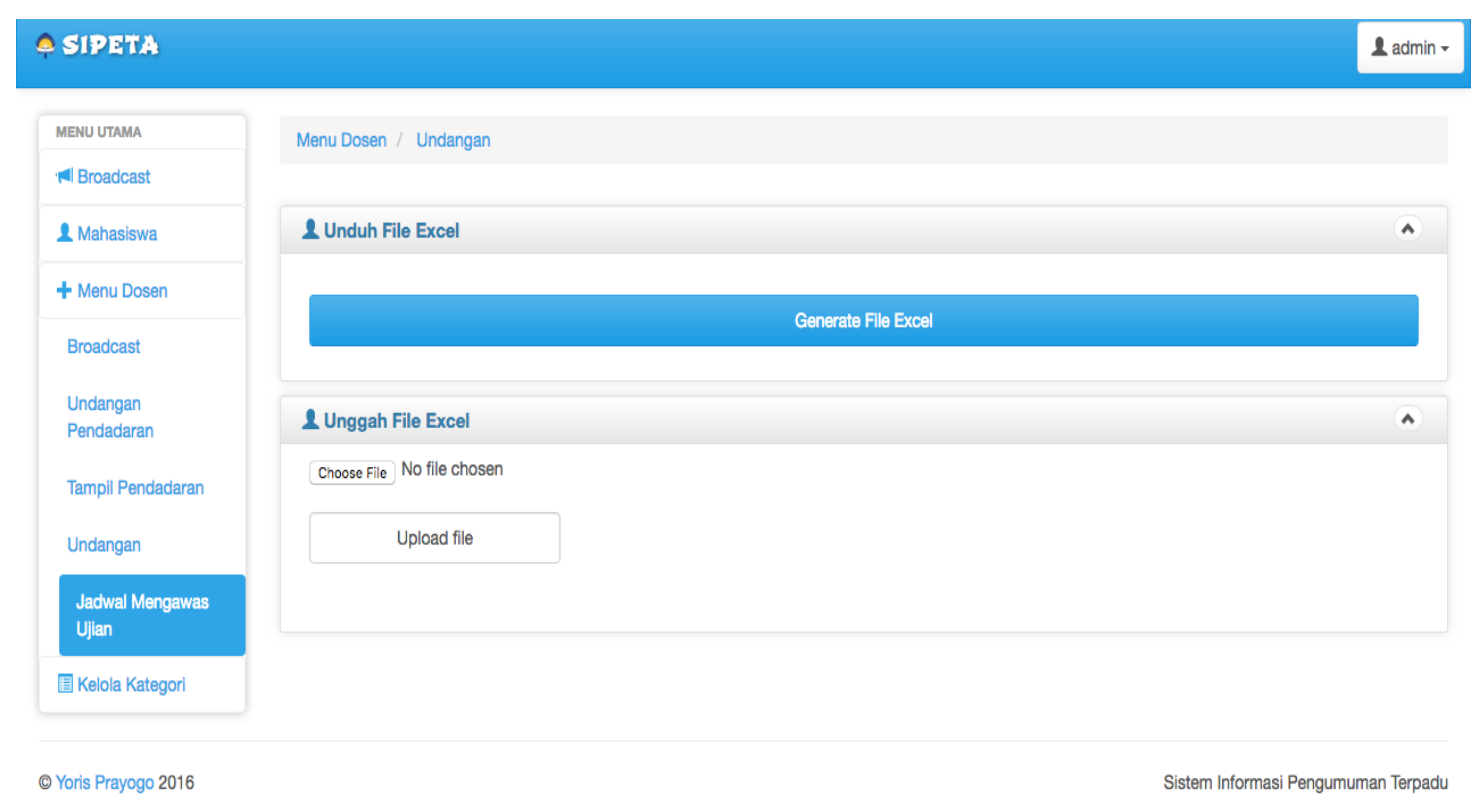

\section{Gambar 9. Kirim Jadwal Mengawas Ujian}

\begin{tabular}{|c|c|c|}
\hline \multicolumn{3}{|l|}{$\leftarrow$ SIPETA } \\
\hline \multicolumn{3}{|c|}{ Jadwal Mengawas Ujian } \\
\hline \multicolumn{3}{|c|}{$\begin{array}{l}\text { Tata Usaha } \\
\text { (1) } 07-07-2016,18: 19: 43\end{array}$} \\
\hline \multirow{2}{*}{\multicolumn{3}{|c|}{$\begin{array}{l}\text { Kepada Yth. Martinus Maslim, S.T., M.T. } \\
\text { Berikut jadwal mengawas ujian semester } \\
\text { anda }\end{array}$}} \\
\hline & & \\
\hline Hari & Sesi & \begin{tabular}{|l|} 
Ruang \\
\end{tabular} \\
\hline Senin, 13 Juni 2016 & 1 & KOORDINATOR \\
\hline Selasa, 14 Juni 2016 & 2 & \begin{tabular}{|l|}
422 \\
\end{tabular} \\
\hline Rabu, 15 Juni 2016 & 1 & 317 \\
\hline Kamis, 16 Juni 2016 & 3 & 422 \\
\hline Minggu, 19 Juni 2016 & 1 & 319 \\
\hline Senin, 20 Juni 2016 & 3 & 319 \\
\hline Rabu, 22 Juni 2016 & 2 & 319 \\
\hline
\end{tabular}

\section{$\triangleleft \quad \Delta \quad \square$}

Gambar 10. Jadwal mengawas yang diterima dosen

Aplikasi mobile dikembangkan untuk broadcast pesan atau informasi kepada mahasiswa yang mengambil kelasnya, melihat jadwal kuliah, melihat kalender agenda perkuliahan, menerima informasi yang dikirimkan oleh TU yaitu undangan pendadaran, undangan rapat, undangan umum, dan jadwal mengawas ujian yang akan diset sebagai event di kalender dan akan mengaktifkan alarm ketika waktunya sudah tiba. Bagi mahasiswa, aplikasi ini digunakan untuk melihat pengumuman perkuliahan yang dikeluarkan oleh pihak TU, melihat pengumuman dari dosen, melihat kalender agenda perkuliahan, dan dapat 
melihat jadwal perkuliahan yang sedang diambil. Aplikasi web digunakan oleh pihak TU dan mempunyai fungsi untuk melakukan broadcast pengumuman perkuliahan kepada semua pemegang aplikasi mobile, membuat serta mencetak undangan pendadaran sekaligus mengirimkan notifikasi ke dosen mengenai ujian pendadaran, mengirimkan undangan yang bersifat umum seperti undangan rapat, pelepasan dan lain-lain.

Arsitektur sistem dapat dilihat pada Gambar 11. Arsitektur sistem terdiri atas tiga buah komponen utama yaitu user atau pengguna sebagai pemakai aplikasi, server aplikasi, serta GCM service yang dimanfaatkan untuk mengirimkan pesan. Koneksi ke KSI (database server) digunakan untuk memverifikasi akun mahasiswa atau dosen dan mengambil profil pengguna yang login. Untuk mengirimkan atau menerima pesan, ada beberapa tahapan yang harus dilalui yaitu: (1) Pengguna login menggunakan login Single Sign On (SSO) yang dimiliki, kemudian aplikasi akan melakukan validasi ke KSI. (2) KSI mengirimkan respon ke aplikasi, jika valid maka KSI akan mengirimkan data pengguna ke device yang meliputi profil pengguna, serta mata kuliah yang diambil. (3) Aplikasi mendaftarkan device pengguna ke GCM Service untuk mendapatkan token. (4) GCM Service mengirimkan respon berupa token ke aplikasi. (5) Aplikasi mengirimkan token dan profil pengguna ke server aplikasi untuk disimpan. Jika pengguna sudah login sebelumnya maka langkah ini dijalankan ketika pengguna dalam hal ini dosen atau Tata Usaha mengirimkan pesan ke mahasiswa. (6) Server aplikasi mengirimkan pesan dan token penerima pesan ke GCM Service. (7) GCM Service mengirimkan pesan ke device penerima. Untuk langkah pertama sampai ke-4 hanya dilakukan pada saat pengguna login untuk pertama kalinya atau pengguna login di device yang berbeda dan belum pernah diinstal aplikasi mobile yang dikembangkan ini.

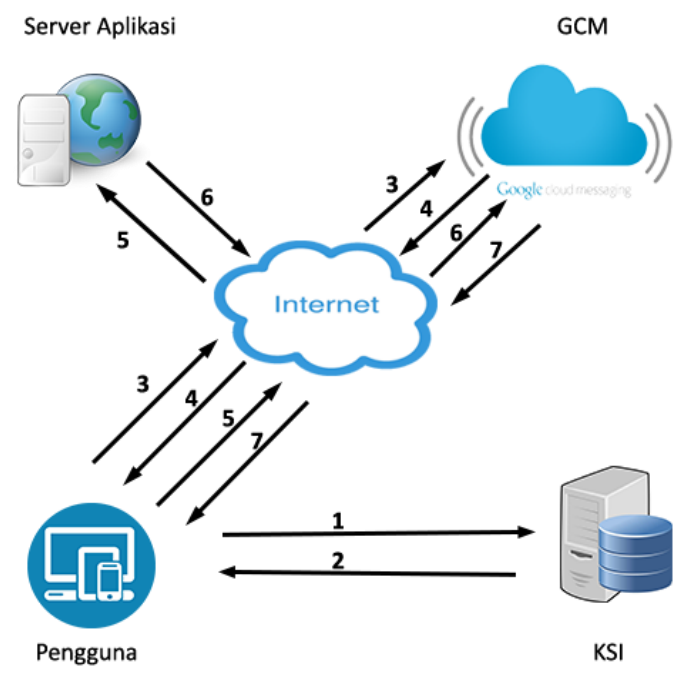

Gambar 11. Arsitektur Sistem

\subsection{Pengujian Aplikasi}

Pengujian aplikasi pengingat jadwal kegiatan akademik ini dilakukan dengan metode black-box oleh pengembang sendiri, dan menggunakan metode kuisioner dan demo kepada responden. Untuk pengujian secara black-box, hasilnya ditampilkan pada Tabel 1, sedangkan untuk pengujian dengan kuisioner dan demo kepada para responden dilakukan kepada 32 orang dari Fakultas Teknologi Industri UAJY dengan rincian 19 orang mahasiswa, 12 orang dosen, dan satu orang staf tata usaha, hasilnya ditampilkan pada Tabel 2. 
Tabel 1. Hasil pengujian aplikasi secara black-box

\begin{tabular}{|c|c|c|}
\hline Fungsi & Prosedur Pengujian & $\begin{array}{c}\text { Hasil } \\
\text { Pengujian }\end{array}$ \\
\hline Login & Pengguna mengisi NPM/NIP. Kemudian menekan tombol masuk. & Handal \\
\hline $\begin{array}{l}\text { Mengirim } \\
\text { Broadcast }\end{array}$ & $\begin{array}{l}\text { Pengguna memilih kelas. Pengguna memilih mahasiswa yang diinginkan. Pengguna mengisi } \\
\text { subjek pesan dan isi pesan. Menekan tombol kirim. }\end{array}$ & Handal \\
\hline $\begin{array}{l}\text { Tampil Jadwal di } \\
\text { Kalender }\end{array}$ & Pengguna memilih tab Kalender. & Handal \\
\hline $\begin{array}{l}\text { Tampil Jadwal } \\
\text { Perkuliahan }\end{array}$ & Pengguna memilih tab jadwal. Pengguna menekan jadwal yang diinginkan. & Handal \\
\hline $\begin{array}{l}\text { Melihat } \\
\text { Broadcast }\end{array}$ & Pengguna memilih tab PESAN. Pengguna memilih pesan yang diinginkan. & Handal \\
\hline $\begin{array}{l}\text { Tambah Event } \\
\text { Kalender }\end{array}$ & Pengguna menekan tombol tambah. Pengguna mengisi jenis event, lokasi, tanggal dan jam. & Handal \\
\hline $\begin{array}{l}\text { Mengirim } \\
\text { Broadcast. }\end{array}$ & $\begin{array}{l}\text { Pengguna memilih penerima pesan. } \\
\text { Pengguna menekan tombol Tulis Pesan. Pengguna mengisikan subjek dan isi pesan. }\end{array}$ & Handal \\
\hline $\begin{array}{l}\text { Membuat } \\
\text { Undangan } \\
\text { Pendadaran }\end{array}$ & $\begin{array}{l}\text { Pengguna mengisi form dengan data-data yang diperlukan yaitu periode, prodi, tanggal dan } \\
\text { waktu, nama mahasiswa, npm mahasiswa, Dosen penguji yang terdiri dari ketua, sekretaris, } \\
\text { anggota } 1 \text {, anggota } 2 \text {, dan tempat dan fasilitas. }\end{array}$ & Handal \\
\hline $\begin{array}{l}\text { Cetak Undangan } \\
\text { Pendadaran }\end{array}$ & $\begin{array}{l}\text { Pengguna memilih bulan dan periode pendadaran. } \\
\text { Pengguna menekan tombol cetak }\end{array}$ & Handal \\
\hline $\begin{array}{l}\text { Membuat } \\
\text { Undangan }\end{array}$ & $\begin{array}{l}\text { Pengguna mengisi form yang tersedia dengan data yang diperlukan yaitu penerima, judul, tanggal } \\
\text { dan waktu, tempat. Pengguna menekan tombol kirim. }\end{array}$ & Handal \\
\hline $\begin{array}{l}\text { Mengirim Jadwal } \\
\text { Mengawas Ujian }\end{array}$ & $\begin{array}{l}\text { Pengguna mengunduh file excel dari server. Pengguna mengisi file excel. Pengguna mengunggah } \\
\text { file excel ke server. }\end{array}$ & Handal \\
\hline $\begin{array}{l}\text { Pengelolaan } \\
\text { Kategori }\end{array}$ & $\begin{array}{l}\text { Pengguna menambah kategori baru. } \\
\text { Pengguna menambah anggota kategori. } \\
\text { Pengguna melihat detail kategori. } \\
\text { Pengguna menghapus kategori. }\end{array}$ & Handal \\
\hline
\end{tabular}

Tabel 2. Hasil pengujian aplikasi secara demo

\begin{tabular}{lccccc}
\hline \multicolumn{1}{c}{ Aspek Pengujian } & \multicolumn{5}{c}{ Persentase Penilaian (\%) } \\
\cline { 2 - 6 } & Sangat Buruk & Buruk & Cukup & Baik & Sangat Baik \\
\hline Antarmuka aplikasi untuk dosen informatif & 0 & 0 & 15 & 46 & 39 \\
\hline Antarmuka aplikasi untuk mahasiswa informatif & 0 & 0 & 16 & 53 & 31 \\
\hline Kemudahan penggunaan aplikasi untuk dosen & 0 & 0 & 8 & 54 & 38 \\
\hline Kemudahan penggunaan aplikasi untuk mahasiswa & 0 & 0 & 5 & 63 & 32 \\
\hline Manfaat aplikasi & 0 & 0 & 0 & 58 & 42 \\
\hline
\end{tabular}

Berdasarkan hasil pengujian dari Tabel 1. dan Tabel 2. maka dapat disimpulkan bahwa aplikasi telah berhasil dibangun dengan kehandalan fungsi-fungsi sesuai dengan harapan, serta memiliki antarmuka yang informatif, mudah digunakan serta bermanfaat. Adapun kelebihan yang dimiliki oleh aplikasi ini adalah sebagai berikut: (1) Dapat Memudahkan pihak TU untuk menyampaikan pesan atau pengumuman kepada mahasiswa secara realtime. (2) Dosen dapat mengatur atau mengorganisir jadwal mengenai perkuliahannya sendiri dengan adanya fitur kalender dan agenda. (3) Dapat memudahkan pihak TU untuk membuat dan mengirim undangan pendadaran karena pihak TU cukup sekali saja mengisi form undangan pendadaran maka sistem akan membuat undangan sekaligus mengirimkan notifikasi ke dosen mengenai jadwal pendadaran. (4) Pesan yang dikirimkan kepada penerima akan sampai secara realtime. Sedangkan keterbatasan dari aplikasi ini adalah sebagai berikut: (1) Pesan yang dikirimkan hanya dapat berupa text dengan panjang maksimal 1024 karakter. (2) Aplikasi mobile yang dikembangkan beru sebatas berjalan pada sistem operasi Android.

\section{Kesimpulan}

Berdasarkan hasil pembahasan pada bab sebelumnya, maka dapat ditarik kesimpulan bahwa aplikasi pengingat jadwal kegiatan akademik di UAJY telah berhasil dibangun dengan kehandalan fungsi-fungsi sesuai dengan harapan, serta memiliki antarmuka yang informatif mudah digunakan serta bermanfaat untuk kalangan dosen, mahasiswa serta TU. 


\section{Referensi}

Akhmad, S. 2013. Aplikasi Pengingat Jadwal Ujian Universitas Gunadarma Pada Smartphone Android. (Online), (http://publication.gunadarma.ac.id/handle/123456789/7639, diakses 30 Desember 2015).

Indrayani, E. 2013. Management of Academic Information System (AIS) at Higher Education in The City Of Bandung. Procedia-Social and Behavioral Sciences, 103, 628-636.

Kalinić, Z. \& Arsovski, S. 2009. Mobile Learning-Quality Standards, Requirements and Constraints. International Journal for Quality research, UDK- 378:004, Scientific Review Paper (1.02), Vol. 3, No. 1, 2009.

Kumar, M., \& Kumar, S. 2013. Implementation of GCM for Mobile Cloud Computing in Android Devices. International Journal of Advanced Research in Computer Science, 4(9).

Lee, Dongcheul. 2011. Designing the Multimedia Push Framework for Mobile Applications. International Journal of Advanced Science and Technology Vol. 32, July, 2011.

Lim, Seung-Ho. 2015. Experimental Comparison of Hybrid and Native Applications for Mobile Systems, International Journal of Multimedia and Ubiquitous Engineering, Vol. 10, No. 3 (2015), pp. 1-12.

Ludwig, Sean. 2012. Study: Mobile app usage grows 35\%, TV \& web not so much. (Online), (http://venturebeat.com/2012/12/05/mobile-app-usage-tv-web-2012/, diakses 2 Februari 2013)

Ramadhan, T., \& Utomo, V. G. 2014. Rancang Bangun Aplikasi Mobile Untuk Notifikasi Jadwal Kuliah Berbasis Android (Studi Kasus: STMIK Provisi Semarang). Jurnal Teknologi Informasi dan Komunikasi, 5(2), 47-55.

Randicha, G., Syafei, W. A., \& Rochim, A. F. 2014. Sistem Penjadwalan Sidang Tugas Akhir Berbasis web Dengan Pesan Pengingat Melalui SMS dan Aplikasi Pada Perangkat Android di Jurusan Teknik Elektro Universitas Diponegoro. TRANSIENT, 3(1), 62-69.

Sujito \& Sundari, R. 2011. Sistem Otomatis Pengingat Jadwal Mengajar Dosen Berbasis SMS (Short Message Service) di STMIK PPKIA Pradnya Paramita Malang (STIMATA). Jurnal Teknologi Informasi: Teori, Konsep, dan Implementasi, 2(1), 84-95.

Sultono, S., Seminar, K. B., \& Erizal, E. 2016. Analysis On Academic Information System Quality Toward User Satisfaction. Bisnis \& Birokrasi Journal, 22(2), 122-129. 